\title{
Coronary Artery Spasm is Associated With an Increased Risk of Incident Diabetes: A Nationwide Population-Based Cohort Study
}

\section{Ming-Jui Hung}

Keelung Chang Gung Memorial Hospital of the CGMF

\section{Nen-Chung Chang}

Taipei Medical University Hospital

\section{Patrick Hu}

University of California Riverside

\section{Tien-Hsing Chen}

Keelung Chang Gung Memorial Hospital of the CGMF

\section{Chun-Tai Mao}

Keelung Chang Gung Memorial Hospital of the CGMF

\section{Chi-Tai Yeh}

Taipei Medical University Shuang Ho Hospital Ministry of Health and Welfare

\section{Ming-Yow Hung ( $\nabla$ myhung6@ms77.hinet.net)}

Taipei Medical University Shuang Ho Hospital Ministry of Health and Welfare https://orcid.org/00000002-6912-7523

\section{Original investigation}

Keywords: Coronary artery spasm, Insulin resistance, Risk factors, Sex difference, Type 2 diabetes

Posted Date: November 24th, 2020

DOl: https://doi.org/10.21203/rs.3.rs-112217/v1

License: (a) (1) This work is licensed under a Creative Commons Attribution 4.0 International License. Read Full License 


\section{Abstract}

\section{Background}

Non-diabetic coronary artery spasm (CAS) without obstructive coronary artery disease increases insulin resistance. We investigated the risk of incident type 2 diabetes (diabetes) associated with CAS.

\section{Methods}

Patient records were retrospectively collected from the Taiwan National Health Insurance Research Database during the period 2000-2012. The matched cohorts consisted of 12,413 patients with CAS and 94,721 patients in the control group.

Results

During the entire follow-up, the incidence of newly-diagnosed diabetes was 22.2 events per 1000 personyears in the CAS group and 13.9 events per 1000 person-years in the control group. The increased risk of CAS-related incident diabetes was observed regardless of sex and length of follow-up. The median time to incident diabetes was 2.9 and 3.5 years in the CAS and the control group $(P<0.001)$, respectively, regardless of sex. Although age did not affect the risk of CAS-related incident diabetes, the risk was less apparent in the subgroups of male, dyslipidemia, chronic obstructive pulmonary disease, stroke, gout and medicated hypertension. However, CAS patients aged $<50$ years compared with patients $\geq 50$ years had a greater risk of incident diabetes in females but not in males. Older CAS patients developed diabetes in a shorter length of time than younger patients.

\section{Conclusion}

CAS is a risk factor for incident diabetes regardless of sex. However, females aged $<50$ years have a more apparent risk for CAS-related diabetes than old females, which is not observed in males. The median time of 2.9 years to incident diabetes warrants close follow-up.

\section{Background}

Coronary artery spasm (CAS), an inflammatory nonobstructive coronary disease characterized by elevated C-reactive protein (CRP) levels, is important because it can result in myocardial ischemia, infarction, and sudden death [1, 2]. The 2 important risk factors for CAS [1], smoking and CRP, are strongly correlated with insulin resistance [3, 4]. Among non-diabetic patients, a significant positive association has been demonstrated between CAS and insulin resistance [5], leading to blood flow-dependent decrease in glucose disposal and hyperglycemia [6]. Although inflammation contributes to synergistic coupling of endothelial dysfunction and insulin resistance [6], treatment with insulin sensitizers to decrease vascular disease has yielded mixed results, perhaps because insulin resistance may promote not only obstructive atherosclerosis [7], but also CAS. On the other hand, racial heterogeneity exists in CAS [1] and insulin resistance [8], the prevalence of type 2 diabetes (diabetes) is not substantially different between 
Japanese [9] and Whites [10]. Hence, CAS is potentially important in modulating the development of diabetes in Asians. It is well established that a long prodromal stage of $\geq 10$ years [11], exists before incident diabetes, suggesting that CAS may start long before the onset of diabetes.

The relationship between cardiovascular disease and glycemia is progressive and begins at a fasting glucose level of $70 \mathrm{mg} / \mathrm{dL}$ and a hemoglobin $\mathrm{A} 1 \mathrm{C}$ level of $5 \%$, values well below those seen in diabetes [12]. Furthermore, the strong association of insulin and endothelial signaling disturbances contributes to the mechanisms of homeostasis between endothelial vasodilationvasoconstriction [13]. While insulin resistance and elevated fasting glucose appear decades before incident diabetes $[7,11]$. the effects of CAS on the risk of incident diabetes in patients without obstructive coronary artery disease have not been investigated. Whether the impact of CAS on incident diabetes is unique, or just a general effect of stress is unknown. Among healthy non-diabetic people, insulin resistance is lower in women than in men [14], reflecting estrogen-facilitated glucose homeostasis in women compared to men. In addition, sex-related differences are found in the incidence of diabetes [15]. We, therefore, sought to determine the risk of prior CAS without obstructive coronary artery disease, with and without regard to sex, on incident diabetes in a nationwide population-based cohort and retrospective case-control study.

\section{Methods}

\section{Study design and subjects}

This was designed as a prospective cohort study of retrospectively-collected data from the National Health Insurance Research Database (NHIRD), which was launched by Taiwan's National Health Institute (NHI) Program in March 1995 and provided approximately 99.8\% coverage for the 23.9 million citizens in Taiwan. The NHIRD contains data for outpatient and inpatient services, including diagnoses, medications, interventions, operations, hospitalizations and emergency visits [16,17]. Diagnosis is registered using the International Classification of Diseases, Ninth Revision, Clinical Modification (ICD-9CM) codes [16, 17]. The study was approved by the Institutional Review Board (ID: 103-0248B) with no informed consent required because of the secondary nature of the deidentified data in the retrospective study design.

The data of the laboratory variables of the NHIRD are not stored in digital format. Hence, in order to provide laboratory values about incident diabetes risk, we conducted a single Shuang Ho hospital study of 252 non-diabetic patients from September 2008 to April 2015 (Additional file 1: Table S1). At baseline, we collected data on demographic information, coexisting illnesses, anthropometric values, use of medications, and laboratory values. Current smoking was defined as having smoked a cigarette within 3 weeks of the cardiac catheterization. Patients underwent echocardiography, when heart rates were recorded, before coronary angiography and within 2 weeks of the last angina. The blood pressure levels were measured at the time of coronary angiography. Among these patients, 140 patients had CAS and 
112 did not have CAS. This hospital study was approved by the Taipei Medical University-Joint Institutional Review Board (No. 201011004 version 1.3). All patients gave written informed consent.

The CAS group comprised adult patients ( $\geq 20$ years) with newly-diagnosed CAS (ICD-9-CM code 4131), with at least 3 outpatient diagnoses or 1 inpatient diagnosis between January 1, 2000 and December 31, 2012 in the NHIRD of the entire Taiwanese population because the prevalence of CAS was not high. The definition of CAS in the NHIRD has been previously reported [18]. Subjects in the control group were identified from a subset of the NHIRD, the Longitudinal Health Insurance Database 2000, which consists of claims data from 1 million randomly sampled people who were alive during the year 2000 and had been followed up from 1997 to 2012. The Longitudinal Health Insurance Database 2000 is representative of the general Taiwanese population in terms of age, sex, or health care costs and has been validated by the National Health Research Institute [19]. The control subjects did not have any previous diagnoses of CAS and obstructive coronary artery disease and were frequency-matched with the CAS group for sex, age, urbanization level, monthly income, and year of CAS diagnosis. The dates of diagnosis of new-onset CAS were assigned as index dates. Notably, the index date of the subjects in the control group was assigned from their matched counterparts in the CAS group. Subjects who had a diagnosis of diabetes before the index date in both the CAS and control groups were excluded (Fig. 1).

\section{Covariates}

The covariates were age at the index date, sex, urbanization level, monthly income, comorbidities (dyslipidemia, chronic obstructive pulmonary disease (COPD), stroke, gout, hepatitis $\mathrm{C}$ virus infection, depression, psychiatric disorders, medicated hypertension) and use of steroid. The comorbidities were verified by the ICD-9-CM diagnostic codes using at least 3 outpatient diagnoses or 1 inpatient diagnosis in the year before the index date. All the information about medication (anti-hypertensive drug or steroid) in the previous year before the index date were extracted from the claims data of outpatient visits or the refill for chronic illness in the pharmacy by using the Anatomical Therapeutic Chemical codes or the Taiwan NHI reimbursement code.

\section{Outcome}

The incident diabetes was the outcome diagnosis, which was validated based on American Diabetes Association criteria and ICD-9-CM codes, where $\geq 4$ outpatient visits corresponded to diagnostic accuracy of $95.7 \%$ [20]. The prescription of oral hypoglycemic agents corresponded to an accuracy of $99 \%$ [21]. Therefore, the occurrence of diabetes required 4 outpatient diagnoses, with the use of any oral hypoglycemic agents. Mortality was defined by withdrawal from the NHI program [22]. All patients were followed from the index date to the date of incident diabetes, date of withdrawal from the NHI program or December 31, 2013, whichever came first.

\section{Statistical analysis}


To minimize potential confounding when comparing the risk of incident diabetes between the CAS and control groups, we applied the inverse probability of treatment weighting (IPTW) based on the propensity score. The propensity score was estimated using a multivariable logistic regression model without considering the interaction effects in which the study group ( $1=\mathrm{CAS}, 0=$ control) was regressed on the selected covariates listed in Table 1, where the follow-up duration was replaced with the index date. We used the weight to estimate average treatment effect and adopted $d$ stabilized weight to mitigate the impact of extreme estimated propensity scores. The balance of the covariates between the groups before and after IPTW was checked using the absolute value of standardized difference between the groups, where a value less than 0.1 was considered a negligible difference.

The risk of incident diabetes between the CAS and control groups was compared using Fine and Gray subdistribution hazard model of a competing risk, which considered all-cause mortality during follow-up. The index dates of the CAS group were based on the diagnosis dates, whereas those of the control group were assigned from the CAS group. Therefore, the control group could have fewer diagnoses at their index dates, which could have resulted in a detection bias and an overestimated effect. To rule out the potential impact of detection bias, patients who received a diagnosis of diabetes within 1 year after the index date were censored (the sensitivity analysis) [23]. The time to incident diabetes between the CAS and control groups was compared using the Mann-Whitney U-test. The trend of time to incident diabetes across age groups was tested using the linear contrast of general linear model.

Finally, subgroup analyses were done to evaluate the possible effect modification of the following prespecified subgroup variables: age ( $<65 \mathrm{vs.} \geq 65$ years), sex, the median age at natural menopause by 50 years in Taiwan [24], dyslipidemia, COPD, stroke, gout and medicated hypertension. A 2-sided $P$ value $<0.05$ was considered significant and no adjustment of multiple testing (multiplicity) was made. All statistical analyses were performed using SAS version 9.4 (SAS Institute, Cary, NC), including the procedures of 'phreg' for the Fine and Gray model and the macro of '\%cif' for generating cumulative incidence function under the Fine and Gray subdistribution hazard method.

For the single hospital study, continuous variables were expressed as mean \pm standard deviation or median value and 25th, 75th percentiles, and log transformation was performed for variables with positive skewness for the subsequent Student's t tests between groups. Categorical variables were analyzed using the $\chi 2$ test. A 2 -sided $P$ value $<0.05$ was considered significant. All statistical analyses were performed with the statistical software package SPSS for Windows (Version 15.0, SPSS Inc., Chicago, IL).

\section{Results}

\section{Patient characteristics}

A total of 12,413 nondiabetic CAS patients and 94,721 nondiabetic non-CAS control subjects were included in the final analysis (Fig. 1). None of these patients has obstructive coronary artery disease. Before IPTW, the CAS group had lower urbanization levels and lower monthly income. The prevalence of 
dyslipidemia, COPD, gout, HCV infection, depression and medicated hypertension was higher in the CAS group than in the control group. In addition, the use of steroid was more common in the CAS group. After IPTW, none of the baseline characteristics were substantially different between groups with all of the absolute standardized difference values $<0.1$. The average follow-up was 6.2 years in both groups (Table 1). In the single hospital study, levels of fasting glucose and glycated hemoglobin were significantly higher in the CAS group (Additional file 1: Table S1).

\section{Sex-specific incidence of diabetes associated with CAS}

About $11.6 \%, 11.4 \%$ and $11.7 \%$ of all, male and female patients with CAS, respectively, developed incident diabetes during a mean follow-up of 6.2 years. During the entire follow-up, the incidence of diabetes was 22.2 events (95\% confidence interval [Cl], 21.8-22.6) per 1000 person-years in the CAS group and 13.9 events $(95 \% \mathrm{Cl}, 13.6-14.2)$ per 1000 person-years in the control group. The annual incidence of diabetes was $2.16 \%$ in males with CAS and $2.26 \%$ in females with CAS. The increased risk of diabetes by CAS was observed at the first year follow-up (subdistribution hazard ratio [SHR], 1.45; 95\% Cl, 1.37-1.54), 3-year follow-up (SHR, 1.39; 95\% Cl, 1.35-1.43), 5-year follow-up (SHR, 1.53; 95\% Cl, 1.48-1.58) and until the end of follow-up (SHR, $1.61 ; 95 \% \mathrm{Cl}, 1.57-1.65)$. The same results were observed when stratifying the analysis by sex (Table 2). After censoring patients who developed incident diabetes within 1 year after the index date in the sensitivity analysis, CAS was still associated with a higher risk of incident diabetes at the 3-year follow-up, 5-year follow-up and until the end of follow-up (Additional file 1: Table S2). While the highest incidence of CAS-related diabetes after age 90 years may be due to sparse data phenomenon, the incidence of sex-specific CAS-related diabetes increased with age until 80 years, and was higher in the middle-aged groups (50-80 years) (Additional file 1: Table S3). The IPTW-adjusted cumulative incidence function of incident diabetes in the CAS and control groups were depicted (Fig. 2A-2B).

\section{Subgroup analysis}

Age, sex, dyslipidemia, COPD, stroke, gout and medicated hypertension were analyzed in the pre-specified subgroup analysis (Fig. 3). The results showed that the increased risk of incident diabetes in association with CAS was less apparent in males and the dyslipidemia, COPD, stroke, gout and medicated hypertension groups ( $P$ for interaction $<0.05$ ). However, when stratified by age (dichotomized as $<50$ or $\geq 50$ years) and sex, the observed increase in the risk of incident diabetes associated with CAS was greater in the younger than older females but not for males ( $P$ for interaction $<0.001$ and 0.824 in the female and male cohorts, respectively).

\section{Time to incident diabetes stratified by age and sex}

The median time to newly-diagnosed diabetes was 2.9 years in the CAS group and 3.5 years in the control group $(P<0.001)$, and did not vary by sex (Fig. 4A). When stratified by age, older CAS patients compared with their younger counterparts had a much shorter length of time before a new case of diabetes was diagnosed ( $P$ trend $<0.001$; Fig. 4B). When further stratified by age and sex, increasing age was 
associated with a shorter length of time before a diagnosis of diabetes in males with CAS ( $P$ trend $<0.001)$. However, this phenomenon was less obvious in females with CAS ( $P$ trend $=0.025$; Fig. $4 \mathrm{~B})$.

\section{Discussion}

In this large cohort study, we found that about $11.6 \%$ of the patients with CAS developed diabetes during a mean follow-up of 6.2 years. During the entire follow-up period, the respective annual incidence of diabetes was $2.22 \%$ in the CAS group and $1.39 \%$ in the control group. The median time to incident diabetes, which did not vary by sex, was 2.9 and 3.5 years in the CAS and the control groups, respectively. CAS was a risk factor for incident diabetes regardless of sex and the length of follow-up. Although age did not affect the risk of incident diabetes associated with CAS, the risk was less apparent in the subgroups of males and patients with dyslipidemia, COPD, stroke, gout, and medicated hypertension. CAS patients aged $<50$ years compared with patients $\geq 50$ years had a greater risk of incident diabetes in females, but not in males. On the other hand, older male CAS patients compared with their younger counterparts developed diabetes in a shorter length of time. In contrast, this age phenomenon was not observed in the female CAS patients $<50$ years.

The sex-specific annual incidences of diabetes in CAS patients was $2.16 \%$ in males and $2.26 \%$ in females, which has not been reported previously. The annual risk of developing diabetes in people with normal glucose level is $0.7 \%$, whereas patients with prediabetes have a yearly risk of up to $10 \%$ [25]. While the prevalence of fasting post-stroke hyperglycemia is $14.6 \%$ in non-diabetic stroke patients [26], about $8 \%$ of non-diabetic stroke survivors develop diabetes during a mean follow-up of 10 years [27], which is more than 2 times higher than expected compared with people from a Dutch general practitioner registry with similar age and sex [28]. Taken together, patients with cardiovascular events have an increased risk of incident diabetes. Furthermore, insulin resistance is the earliest metabolic abnormality detected in subjects destined to develop diabetes [29], and precipitously increased with HbA1c levels $>5.5 \%$. Although the higher short-term risk of developing diabetes among CAS patients than controls may be attributed to earlier medical attention, the CAS patients in our single hospital study had an average glycated hemoglobin level 5.8\%, which are considered high-risk for diabetes by the American Diabetes Association [29]. On the other hand, insulin resistance and atherosclerosis could represent independent responses to the disruption of cellular homeostasis [7]. Inactivation of the insulin receptor decreases mouse atherosclerosis lesions [30,31], which become more complex at later time points [30,31], suggesting that insulin resistance could have differential adaptive effects on CAS and atherosclerotic obstructive coronary artery disease.

The age-associated incidence of CAS-related diabetes was similar to previous studies in patients after stroke [26] and the general population [15]. However, age did not affect the risk of CAS-related incident diabetes, suggesting that CAS may be a stronger modulating factor than age for incident diabetes. Sex differences in risk of incident diabetes arise from sociocultural processes, such as stress [15], which has a greater impact on incident diabetes in females than males [15]. Therefore, the sex differences in CASrelated diabetes result from the effects other than hormones. Furthermore, when glucose tolerance 
deteriorates, insulin sensitivity in women is reduced more dramatically than in men [15], contributing to the higher risk of incident diabetes in females than males with CAS, which may partly explain why women show better insulin sensitivity if they are normoglycemic [15]. Although dyslipidemia contributes to acquired insulin resistance [32], dyslipidemia did not increase the risk of diabetes in CAS patients, which may be due to the more important role of the reciprocal relationships between impaired insulinstimulated blood flow and glucose uptake [6] than dyslipidemia in CAS. While COPD with associated insulin resistance has been demonstrated to be a risk factor for incident diabetes [33], CAS had a higher risk of incident diabetes in patients without COPD than with COPD, suggesting that impaired lung function in CAS does not increase the risk of diabetes. Previous studies showed that more than half of non-diabetic stroke patients have pre-diabetes 3 months after stroke [34]. However, the risk of incident diabetes was higher in CAS patients without stroke than with stroke when impaired glucose metabolism in the acute stress period should have subsided, suggesting that it is a reflection of unrecognized incident diabetes and not caused by stress of the acute phase of cardiovascular events. Although gout contributes to insulin resistance and increased levels of CRP [35], gout did not increase the risk of CASrelated diabetes. Hence, CRP could be an epiphenomenon in the development of CAS-related diabetes. While hypertension is less closely associated with insulin resistance than are other metabolic abnormalities [36], the antihypertensive treatment improves both insulin sensitivity and endothelial function [13]. Therefore, the risk of diabetes was more apparent in CAS patients without hypertension or with non-medicated hypertension than in CAS patients with medicated hypertension. Taken together, the increased risk of incident diabetes associated with CAS was more apparent in females aged $<50$ years and patients without dyslipidemia, COPD, stroke, gout or medicated hypertension. Prospective studies are needed to examine this hypothesis.

While the incidence of diabetes in the general population reaches the highest rates in the very old females [15], CAS patients aged $<50$ than $\geq 50$ years have a greater risk of incident diabetes in females but not in males, which seems to be related to sex differences in pre-diabetes [15]. Moreover, the essential interaction between estrogen receptor $\alpha$ and caveolin- 1 for localization of estrogen receptor to the plasma membrane in endothelial cells [37] may be abrogated in CAS because increased Interleukin-6 levels inhibit endothelial nitric oxide synthase activation by increasing endothelial nitric oxide synthase binding to caveolin-1 in vascular endothelial cells [38]. Although the complex interactions between insulin resistance, hyperglycemia and estrogen impairs the endothelial response in females more dramatically than in males [15], as age reduces the benefits of estrogen on insulin-mediated glucose disposal [39] in females, sex differences are reduced. Our data suggest that the sex-specific effects of CAS attenuate the protective effect of female sex, leading to a higher risk of incident diabetes in females than in males.

Consistent with a previous study showing that the rate of onset of diabetes was greater for men than for women [40], the median time to CAS-related incident diabetes was slightly earlier in males rather than females. Moreover, insulin resistance occurs with aging [41]. Thus, older rather than younger males with CAS may be less sensitive to insulin, leading to a shorter length of time in developing diabetes. However, age did not reduce the time to incident diabetes in CAS females aged $<50$ years, suggesting a protective role for premenopausal estrogen against incident diabetes. Although we did not perform any analyses of 
lifestyle or dietary habits among CAS patients, these factors could be key variables that could affect the length of time before incident diabetes develops between males and females with CAS. Because the early onset of diabetes is associated with a more aggressive diabetic course, a better understanding of the potentially modifiable precursors to cardiometabolic disease, such as CAS, is essential.

Our study has limitations. First, the major limitation is the use of diagnoses in an electronic health record, and thus these diagnoses lack the rigor of a research set of objective definitions. To mitigate the impact of misclassification bias due to coding error, we required that CAS has at least 3 outpatient diagnoses or 1 inpatient diagnosis, and for diabetes, we required $\geq 4$ outpatient visits and the prescription of antidiabetic drugs. Second, while controlling for confounding factors using multivariate modeling, personal information such as smoking habits and substance use were not available because of the privacy policy governing this database. For consideration of these confounders, socioeconomic indicators such as sex, monthly income and place of residence were adjusted in the regression analyses. However, Taiwan has a particularly high male smoking prevalence and much lower female prevalence among adults with the male-to-female ratio of 11 ( $46.8 \%$ and $4.3 \%$, respectively) [42]. Hence, sex could be a proxy variable for smoking. Third, data on obesity and body mass index were not available in the NHIRD. However, obesity may not affect the temporal relationship between CAS and diabetes because obesity does not contribute to the pathogenesis of CAS [43]. Fourth, our study population was a group of potentially health-conscious individuals. Therefore, the timeline for diabetes in our study population could be steeper than that in the general population. Fifth, to maximize specificity, we identified incident diabetes cases based on a diagnosis code and a dispensing code for antidiabetic drugs. Even though we adjusted for 14 demographic, comorbidity and medication variables using propensity score weighting, the study may be subject to residual confounding by a family history of diabetes, physical activity, menopausal status among women, and diet. Sixth, given no ICD-9-CM codes for menopause, future formal clinical studies are required to investigate the time sequence of CAS and menopause as a tool for sex analysis. Finally, a limitation of matching is that unexposed individuals not matched to exposed individuals, and possibly some unmatched exposed individuals, are excluded from the analysis, leading to a decrease in the estimated association. However, in our study with many covariates, the propensity score offers a straightforward approach to reduce the dimensionality of the array of confounders.

\section{Conclusion}

CAS is a potentially life-threatening and important early cardiovascular risk factor for incident diabetes regardless of sex and the length of follow-up. However, CAS patients aged $<50$ years compared with patients $\geq 50$ years had a greater risk of incident diabetes in females but not in males. Therefore, the diagnosis of CAS is important to detect such sex-specific differences in CAS-related pre-diabetes. Our study suggests that new physiological studies designed to unravel the mechanism of CAS-related incident diabetes are warranted.

\section{Abbreviations}


CAS: coronary artery spasm; Cl: confidence interval; COPD: chronic obstructive pulmonary disease; CRP: C-reactive protein; ICD-9-CM: International Classification of Diseases, Ninth Revision, Clinical Modification; NHI: National Health Institute; NHIRD: National Health Insurance Research Database; SHR: subdistribution hazard ratio.

\section{Declarations}

\section{Acknowledgments}

We thank Alfred Hsing-Fen Lin and Zoe Ya-Jhu Syu for their assistance in statistical analysis.

\section{Authors' contributions}

M.-J., N.-C., and M.-Y. conceived and designed the study. T.-H. conducted database management. P. and C.-T. contributed to discussion and reviewed the manuscript. T.-H. and M.-Y. conducted the statistical analysis. N.-C., T.-H., C.-T., M.-J. and M.-Y. analyzed and interpreted the data. M.-J., N.-C. and M.-Y. wrote the first draft. M.-Y. critically revised the manuscript. M.-J. and N.-C. equally contributed to this work. All authors read and approved the final manuscript.

\section{Funding}

This work received grants from National Science Council of Taiwan to M.-Y.H. (MOST-108-2314-B-038119-MY3), from Taipei Medical University (107TMU-SHH-02) to M.-Y.H. and from Chang Gung Memorial Hospital (CLRPG2J0011) to M.-J. H. They had no role in design, analysis, interpretation, reporting of results or the decision to develop this manuscript.

\section{Availability of data and materials}

The datasets used in this study are not publicly available because of information governance restrictions, and held by the Taiwan Ministry of Health and Welfare, which must approve an application to access this data. Any researcher interested in accessing this dataset can submit an application form to the Ministry of Health and Welfare requesting access. Please contact the staff of Ministry of Health and Welfare (Email: stcarolwu@mohw.gov.tw) for further assistance. Taiwan Ministry of Health and Welfare Address: No.488, Sec. 6, Zhongxiao E. Rd., Nangang Dist., Taipei City 115, Taiwan (R.O.C.). Phone: +886-2-85906848 .

\section{Ethics approval and consent to participate}

The study was approved by the Institutional Review Board (ID: 103-0248B) with no informed consent required because of the secondary nature of the deidentified data in the retrospective study design. The hospital study was approved by the Taipei Medical University-Joint Institutional Review Board (No. 201011004 version 1.3). All patients gave written informed consent. 
Not applicable.

\section{Competing interests}

The authors declare that they have no competing interests.

\section{Author details}

${ }^{1}$ Division of Cardiology, Department of Medicine and Community Medicine Research Center, Chang Gung Memorial Hospital, Keelung, Chang Gung University College of Medicine, Keelung City, Taiwan. ${ }^{2}$ Division of Cardiology, Department of Internal Medicine, Taipei Medical University Hospital, Taipei, Taiwan.

${ }^{3}$ Division of Cardiology, Department of Internal Medicine, School of Medicine, College of Medicine, Taipei Medical University, Taipei, Taiwan. ${ }^{4}$ Taipei Heart Institute, Taipei Medical University, Taipei, Taiwan. ${ }^{5}$ University of California, Riverside, Riverside, California, United States of America. ${ }^{6}$ Department of Cardiology, Riverside Medical Clinic, Riverside, California, United States of America. ${ }^{7}$ Department of Medical Research and Education, Shuang Ho Hospital, Taipei Medical University, New Taipei City, Taiwan. ${ }^{8}$ Department of Medical Laboratory Science and Biotechnology, Yuanpei University of Medical Technology, Hsinchu City 300, Taiwan. ${ }^{9}$ Division of Cardiology, Department of Internal Medicine, Shuang Ho Hospital, Taipei Medical University, New Taipei City, Taiwan.

\section{References}

1. Hung MY, Kounis NG, Lu MY, Hu P. Myocardial Ischemic Syndromes, Heart Failure Syndromes, Electrocardiographic Abnormalities, Arrhythmic Syndromes and Angiographic Diagnosis of Coronary Artery Spasm: Literature Review. Int J Med Sci. 2020;17:1071-82.

2. Pearson JT, Jenkins MJ, Edgley AJ, Sonobe T, Joshi M, Waddingham MT, et al. Acute Rho-kinase inhibition improves coronary dysfunction in vivo, in the early diabetic microcirculation. Cardiovasc Diabetol. 2013;12:111.

3. Eliasson B, Attvall S, Taskinen MR, Smith U. The insulin resistance syndrome in smokers is related to smoking habits. Arterioscler Thromb. 1994;14:1946-50.

4. Festa A, D'Agostino R Jr, Howard G, Mykkänen L, Tracy RP, Haffner SM. Chronic subclinical inflammation as part of the insulin resistance syndrome: the Insulin Resistance Atherosclerosis Study (IRAS). Circulation. 2000;102:42-7.

5. Kang KW, Choi BG, Rha SW. Impact of Insulin Resistance on Acetylcholine-Induced Coronary Artery Spasm in Non-Diabetic Patients. Yonsei Med J. 2018;59:1057-63.

6. Kim JA, Montagnani M, Koh KK, Quon MJ. Reciprocal relationships between insulin resistance and endothelial dysfunction: molecular and pathophysiological mechanisms. Circulation. 2006;113:1888-904.

7. Semenkovich CF. Insulin resistance and atherosclerosis. J Clin Invest. 2006;116:1813-22. 
8. Sagesaka H, Sato Y, Someya Y, Tamura Y, Shimodaira M, Miyakoshi T, et al. Type 2 Diabetes: When Does It Start? J Endocr Soc. 2018;2:476-84.

9. Mukai N, Doi Y, Ninomiya T, Hirakawa Y, Nagata M, Yoshida D, et al. Trends in the prevalence of type 2 diabetes and prediabetes in community-dwelling Japanese subjects: The Hisayama Study. J Diabetes Investig. 2014;5:162-9.

10. Menke A, Casagrande S, Geiss L, Cowie CC. Prevalence of and Trends in Diabetes Among Adults in the United States, 1988-2012. JAMA. 2015;314:1021-9.

11. Tabák AG, Jokela M, Akbaraly TN, Brunner EJ, Kivimäki M, Witte DR. Trajectories of glycaemia, insulin sensitivity, and insulin secretion before diagnosis of type 2 diabetes: an analysis from the Whitehall II study. Lancet. 2009;373:2215-21.

12. Khaw KT, Wareham N, Bingham S, Luben R, Welch A, Day N. Association of hemoglobin A1c with cardiovascular disease and mortality in adults: the European prospective investigation into cancer in Norfolk. Ann. Intern Med. 2004;141:413-20.

13. Janus A, Szahidewicz-Krupska E, Mazur G, Doroszko A. Insulin Resistance and Endothelial Dysfunction Constitute a Common Therapeutic Target in Cardiometabolic Disorders. Mediators Inflamm. 2016;2016:3634948.

14. Nuutila P, Knuuti MJ, Mäki M, Laine H, Ruotsalainen $U$, Teräs $M$, et al. Gender and insulin sensitivity in the heart and in skeletal muscles. Studies using positron emission tomography. Diabetes. 1995;44:31-6.

15. Kautzky-Willer A, Harreiter J, Pacini G. Sex and Gender Differences in Risk, Pathophysiology and Complications of Type 2 Diabetes Mellitus. Endocr Rev. 2016;37:278-316.

16. Hsing AW, loannidis JP. Nationwide population science: lessons from the Taiwan national health insurance research database. JAMA internal medicine. 2015;175:1527-9.

17. Hsieh CY, Su CC, Shao SC, Sung SF, Lin SJ, Kao Yang YH, et al. Taiwan's National Health Insurance Research Database: past and future. Clin Epidemiol. 2019;11:349-58.

18. Hung MY, Mao CT, Hung MJ, Wang JK, Lee HC, Yeh CT, et al. Coronary Artery Spasm as Related to Anxiety and Depression: A Nationwide Population-Based Study. Psychosom Med. 2019;81:237-45.

19. Wu XF, Huang JY, Chiou JY, Chen HH, Wei JC, Dong LL. Increased risk of coronary heart disease among patients with primary Sjögren's syndrome: a nationwide population-based cohort study. Sci Rep. 2018;8:2209.

20. Lin CC, Lai MS, Syu CY, Chang SC, Tseng FY. Accuracy of diabetes diagnosis in health insurance claims data in Taiwan. Journal of the Formosan Medical Association. 2005;104:157-63.

21. Wu CS, Lai MS, Gau SS, Wang SC, Tsai HJ. Concordance between patient self-reports and claims data on clinical diagnoses, medication use, and health system utilization in Taiwan. PLOS ONE. 2014;9:e112257.

22. Wu CY, Chen YJ, Ho HJ, Hsu YC, Kuo KN, Wu MS, et al. Association between nucleoside analogues and risk of hepatitis $B$ virus-related hepatocellular carcinoma recurrence following liver resection. JAMA. 2012;308:1906-14. 
23. de Jong RGPJ,Burden AM, de Kort S, van Herk-Sukel MPP, Vissers PAJ, Janssen PKC, et al. Impact of detection bias on the risk of gastrointestinal cancer and its subsites in type 2 diabetes mellitus. European Journal of Cancer. 2017;79:61-71.

24. Shen TY, Chen HJ, Pan WH, Yu T. Secular trends and associated factors of age at natural menopause in Taiwanese women. Menopause. 2019;26:499-505.

25. Roquer J, Rodríguez-Campello A, Cuadrado-Godia E, Giralt-Steinhauer E, Jiménez-Conde J, Dégano IR, et al. Ischemic stroke in prediabetic patients. J Neurol. 2014;261:1866-70.

26. Vancheri F, Curcio M, Burgio A, Salvaggio S, Gruttadauria G, Lunetta MC, et al. Impaired glucose metabolism in patients with acute stroke and no previous diagnosis of diabetes mellitus. QJM. 2005;98:871-8.

27. Rutten-Jacobs LC, Keurlings PA, Arntz RM, Maaijwee NA, Schoonderwaldt HC, Dorresteijn LD, et al. High incidence of diabetes after stroke in young adults and risk of recurrent vascular events: the FUTURE study. PLoS One. 2014;9:e87171.

28. Poos MJJC. Diabetes mellitus: prevalence, incidence and death according to age and gender. Volksgezondheid Toekomst Verkenning, Nationaal Kompas Volksgezondheid. Bilthoven: RIVM. 2011.

29. Kanat M, Winnier D, Norton L, Arar N, Jenkinson C, Defronzo RA, et al. The relationship between \{beta\}-cell function and glycated hemoglobin: results from the veterans administration genetic epidemiology study. Diabetes Care. 2011;34:1006-10.

30. Baumgartl J, Baudler S, Scherner M, Babaev V, Makowski L, Suttles J, et al. Myeloid lineage cellrestricted insulin resistance protects apolipoproteinE-deficient mice against atherosclerosis. Cell Metab. 2006;3:247-256.

31. Han S, Liang CP, DeVries-Seimon T, Ranalletta M, Welch CL, Collins-Fletcher K, et al. Macrophage insulin receptor deficiency increases ER stress-induced apoptosis and necrotic core formation in advanced atherosclerotic lesions. Cell Metab. 2006;3:257-66.

32. Shulman GI. Cellular mechanisms of insulin resistance. J Clin Invest. 2000;106:171-6.

33. Rana JS, Mittleman MA, Sheikh J, Hu FB, Manson JE, Colditz GA, et al. Chronic obstructive pulmonary disease, asthma, and risk of type 2 diabetes in women. Diabetes Care. 2004;27:2478-84.

34. Gray CS, Scott JF, French JM, Alberti KG, O'Connell JE. Prevalence and prediction of unrecognised diabetes mellitus and impaired glucose tolerance following acute stroke. Age Ageing. 2004;33:71-7.

35. Fiorentino TV, Sesti F, Succurro E, Pedace E, Andreozzi F, Sciacqua A, et al. Higher serum levels of uric acid are associated with a reduced insulin clearance in non-diabetic individuals. Acta Diabetol. 2018;55:835-42.

36. Bonora E, Kiechl S, Willeit J, Oberhollenzer F, Egger G, Targher G, et al. Prevalence of insulin resistance in metabolic disorders: the Bruneck Study. Diabetes. 1998;47:1643-9.

37. Chambliss KL, Yuhanna IS, Mineo C, Liu P, German Z, Sherman TS, et al. Estrogen receptor alpha and endothelial nitric oxide synthase are organized into a functional signaling module in caveolae. Circ Res. 2000;87:E44-52. 
38. Hung MJ, Cherng WJ, Hung MY, Wu HT, Pang JH. Interleukin-6 inhibits endothelial nitric oxide synthase activation and increases endothelial nitric oxide synthase binding to stabilized caveolin-1 in human vascular endothelial cells. J Hypertens. 2010;28:940-51.

39. Pereira RI, Casey BA, Swibas TA, Erickson CB, Wolfe P, Van Pelt RE. Timing of estradiol treatment after menopause may determine benefit or harm to insulin action. J Clin Endocrinol Metab. 2015;100:4456-62.

40. Harris MI, Flegal KM, Cowie CC, Eberhardt MS, Goldstein DE, Little RR, et al. Prevalence of diabetes, impaired fasting glucose, and impaired glucose tolerance in U.S. adults. The Third National Health and Nutrition Examination Survey, 1988-1994. Diabetes Care. 1998;21:518-24.

41. Ahrén B, Pacini G. Importance of quantifying insulin secretion in relation to insulin sensitivity to accurately assess $\beta$ cell function in clinical studies. Eur J Endocrinol. 2004;150:97-104.

42. Wen CP, Levy DT, Cheng TY, Hsu CC. Smoking behaviour in Taiwan, 2001. Tob Control. 2005;14(Suppl 1): i51-5.

43. Hung MJ, Hsu KH, Chang NC, Hung MY. Increased Numbers of Coronary Events in Winter and Spring Due to Coronary Artery Spasm: Effect of Age, Sex, Smoking, and Inflammation. J Am Coll Cardiol. 2015;65:2047-8.

\section{Tables}

Table 1 Baseline characteristics of patients with CAS and control subjects without obstructive coronary artery disease 


\begin{tabular}{|c|c|c|c|c|c|c|c|}
\hline \multirow{3}{*}{ Variable } & \multicolumn{4}{|c|}{ Data before IPTWa } & \multicolumn{3}{|c|}{ Data after IPTW' } \\
\hline & $\begin{array}{l}\text { Nondiabetic } \\
\text { CAS }\end{array}$ & $\begin{array}{l}\text { Nondiabetic } \\
\text { Control }\end{array}$ & STD & & $\begin{array}{l}\text { Nondiabetic } \\
\text { CAS }\end{array}$ & $\begin{array}{l}\text { Nondiabetic } \\
\text { Control }\end{array}$ & STD \\
\hline & $(n=12,413)$ & $(n=94,721)$ & & & & & \\
\hline Age, years & $56.3 \pm 14.3$ & $56.7 \pm 15.9$ & -0.03 & & $57.5 \pm 14.7$ & $56.7 \pm 15.8$ & 0.05 \\
\hline Male & $6,338(51.1)$ & $\begin{array}{l}48,203 \\
(50.9)\end{array}$ & $<0.01$ & & 50.5 & 50.9 & -0.01 \\
\hline \multicolumn{8}{|l|}{$\begin{array}{l}\text { Urbanization } \\
\text { level }\end{array}$} \\
\hline Low & $1,950(15.7)$ & $\begin{array}{l}10,390 \\
(11.0)\end{array}$ & 0.14 & - & 10.7 & 11.5 & -0.03 \\
\hline Moderate & $5,107(41.1)$ & $\begin{array}{l}26,852 \\
(28.3)\end{array}$ & 0.27 & - & 29.8 & 30 & $<0.01$ \\
\hline High & $3,362(27.1)$ & $\begin{array}{l}30,746 \\
(32.5)\end{array}$ & -0.12 & - & 31.1 & 31.8 & -0.02 \\
\hline Very High & $1,994(16.1)$ & $\begin{array}{l}26,733 \\
(28.2)\end{array}$ & -0.30 & - & 28.5 & 26.8 & 0.04 \\
\hline $\begin{array}{l}\text { Monthly income, } \\
\text { NTDS }\end{array}$ & - & - & & - & - & - & \\
\hline $0-17,880$ & $3,723(30.0)$ & $\begin{array}{l}42,610 \\
(45.0)\end{array}$ & -0.31 & & 44 & 43.2 & 0.02 \\
\hline $17,881-22,800$ & $4,417(35.6)$ & $\begin{array}{l}25,499 \\
(26.9)\end{array}$ & 0.19 & & 27.3 & 28 & -0.02 \\
\hline$>22,800$ & $4,273(34.4)$ & $\begin{array}{l}26,612 \\
(28.1)\end{array}$ & 0.14 & & 28.7 & 28.8 & $<0.01$ \\
\hline Comorbidity & - & - & & - & - & - & \\
\hline Dyslipidemia & $3,012(24.3)$ & $4,768(5.0)$ & 0.57 & & 8.5 & 7.6 & 0.03 \\
\hline $\begin{array}{l}\text { Chronic } \\
\text { obstructive } \\
\text { pulmonary } \\
\text { disease }\end{array}$ & $1,358(10.9)$ & $3,800(4.0)$ & 0.27 & & 5.3 & 4.9 & 0.02 \\
\hline Stroke & $558(4.5)$ & $2,593(2.7)$ & 0.09 & & 4 & 3 & 0.06 \\
\hline Gout & $1,010(8.1)$ & 3,557 (3.8) & 0.19 & & 5.8 & 4.4 & 0.06 \\
\hline $\begin{array}{l}\text { Hepatitis C virus } \\
\text { infection }\end{array}$ & $217(1.7)$ & $650(0.7)$ & 0.10 & & 1 & 0.8 & 0.02 \\
\hline Depression & $325(2.6)$ & $846(0.9)$ & 0.13 & & 1.3 & 1.1 & 0.02 \\
\hline
\end{tabular}




\begin{tabular}{|c|c|c|c|c|c|c|c|}
\hline \multirow[b]{2}{*}{ Variable } & \multicolumn{3}{|c|}{ Data before IPTWa } & & \multicolumn{3}{|c|}{ Data after IPTW ${ }^{b}$} \\
\hline & $\begin{array}{l}\text { Nondiabetic } \\
\text { CAS } \\
(n=12,413)\end{array}$ & $\begin{array}{l}\text { Nondiabetic } \\
\text { Control } \\
(n=94,721)\end{array}$ & STD & & $\begin{array}{l}\text { Nondiabetic } \\
\text { CAS }\end{array}$ & $\begin{array}{l}\text { Nondiabetic } \\
\text { Control }\end{array}$ & STD \\
\hline $\begin{array}{l}\text { Psychiatric } \\
\text { disorders }\end{array}$ & $41(0.3)$ & $590(0.6)$ & -0.04 & & 0.6 & 0.6 & $<0.01$ \\
\hline $\begin{array}{l}\text { Medicated } \\
\text { hypertension }\end{array}$ & 5,125 (41.3) & $\begin{array}{l}11,797 \\
(12.5)\end{array}$ & 0.69 & & 17.6 & 16.2 & 0.04 \\
\hline Steroid & $284(2.3)$ & $822(0.9)$ & 0.11 & - & 1.3 & 1.1 & 0.02 \\
\hline $\begin{array}{l}\text { Follow-up } \\
\text { duration, years }\end{array}$ & $5.3 \pm 3.4$ & $6.4 \pm 3.8$ & -0.28 & & $6.2 \pm 3.6$ & $6.2 \pm 3.8$ & $<0.01$ \\
\hline
\end{tabular}

IPTW, inverse probability of treatment weighting; CAS, coronary artery spasm; STD, standardized difference.

${ }^{\mathrm{a}}$ Data were presented as frequency (percentage) or mean \pm standard deviation.

${ }^{\mathrm{b}}$ Data were presented as percentage or mean \pm standard deviation.

Table 2 Incidence of diabetes associated with CAS without obstructive coronary artery disease stratified by sex ${ }^{a}$ 


\begin{tabular}{|c|c|c|c|c|c|c|c|}
\hline \multirow[b]{2}{*}{$\begin{array}{l}\text { Population / } \\
\text { follow-up }\end{array}$} & \multicolumn{3}{|c|}{ Nondiabetic CAS } & \multicolumn{4}{|c|}{ Nondiabetic Control } \\
\hline & $\begin{array}{l}\text { No. } \\
\text { of }\end{array}$ & $\begin{array}{l}\text { ID }(95 \% \\
\mathrm{Cl})^{\mathrm{b}}\end{array}$ & $\begin{array}{l}\text { ID }(95 \% \\
\mathrm{Cl})^{\star}\end{array}$ & $\begin{array}{l}\text { No. } \\
\text { of }\end{array}$ & $\begin{array}{l}\text { ID }(95 \% \\
\mathrm{Cl})^{\mathrm{b}}\end{array}$ & $\begin{array}{l}\text { ID }(95 \% \\
\mathrm{Cl})^{\star}\end{array}$ & $\begin{array}{l}\text { SHR of } \\
\text { CAS }^{*}\end{array}$ \\
\hline & Case & & & Case & & & $(95 \% \mathrm{Cl})$ \\
\hline All & - & & & - & & & \\
\hline 1 year & 337 & $\begin{array}{l}29.1 \\
(26.0- \\
32.2)\end{array}$ & $\begin{array}{l}24.9 \\
(23.9- \\
25.8)\end{array}$ & 1,445 & $\begin{array}{l}15.7 \\
(14.9- \\
16.5)\end{array}$ & $\begin{array}{l}17.2 \\
(16.4- \\
18.0)\end{array}$ & $\begin{array}{l}1.45 \\
(1.37- \\
1.54)\end{array}$ \\
\hline 3 year & 733 & $\begin{array}{l}24.1 \\
(22.3- \\
25.8)\end{array}$ & $\begin{array}{l}21.4 \\
(20.9- \\
22.0)\end{array}$ & 3,380 & $\begin{array}{l}13.6 \\
(13.2- \\
14.1)\end{array}$ & $\begin{array}{l}14.6 \\
(14.1- \\
15.0)\end{array}$ & $\begin{array}{l}1.39 \\
(1.35- \\
1.43)\end{array}$ \\
\hline 5 year & 1,026 & $\begin{array}{l}23.4 \\
(21.9- \\
24.8)\end{array}$ & $\begin{array}{l}21.2 \\
(20.7- \\
21.6)\end{array}$ & 4,898 & $\begin{array}{l}13.3 \\
(12.9- \\
13.6)\end{array}$ & $\begin{array}{l}14.1 \\
(13.7- \\
14.4)\end{array}$ & $\begin{array}{l}1.53 \\
(1.48- \\
1.58)\end{array}$ \\
\hline Overall & 1,434 & $\begin{array}{l}23.5 \\
(22.3- \\
24.7)\end{array}$ & $\begin{array}{l}22.2 \\
(21.8- \\
22.6)\end{array}$ & 7,593 & $\begin{array}{l}13.3 \\
(13.0- \\
13.6)\end{array}$ & $\begin{array}{l}13.9 \\
(13.6- \\
14.2)\end{array}$ & $\begin{array}{l}1.61 \\
(1.57- \\
1.65)\end{array}$ \\
\hline Male & - & & & & & & \\
\hline 1 year & 176 & $\begin{array}{l}29.8 \\
(25.4- \\
34.2)\end{array}$ & $\begin{array}{l}25.7 \\
(24.3- \\
27.1)\end{array}$ & 761 & $\begin{array}{l}16.4 \\
(15.2- \\
17.5)\end{array}$ & $\begin{array}{l}17.6 \\
(16.5- \\
18.8)\end{array}$ & $\begin{array}{l}1.47 \\
(1.35- \\
1.60)\end{array}$ \\
\hline 3 year & 375 & $\begin{array}{l}24.2 \\
(21.8- \\
26.7)\end{array}$ & $\begin{array}{l}21.6 \\
(20.8- \\
22.3)\end{array}$ & 1,793 & $\begin{array}{l}14.4 \\
(13.7- \\
15.0)\end{array}$ & $\begin{array}{l}15.3 \\
(14.6- \\
15.9)\end{array}$ & $\begin{array}{l}1.31 \\
(1.25- \\
1.37)\end{array}$ \\
\hline 5 year & 506 & $\begin{array}{l}22.7 \\
(20.7- \\
24.6)\end{array}$ & $\begin{array}{l}20.3 \\
(19.7- \\
20.9)\end{array}$ & 2,532 & $\begin{array}{l}13.7 \\
(13.1- \\
14.2)\end{array}$ & $\begin{array}{l}14.4 \\
(13.9- \\
14.9)\end{array}$ & $\begin{array}{l}1.42 \\
(1.35- \\
1.49)\end{array}$ \\
\hline Overall & 723 & $\begin{array}{l}23.2 \\
(21.5- \\
24.9)\end{array}$ & $\begin{array}{l}21.6 \\
(21.1- \\
22.2)\end{array}$ & 3,990 & $\begin{array}{l}14.0 \\
(13.5- \\
14.4)\end{array}$ & $\begin{array}{l}14.6 \\
(14.2- \\
15.0)\end{array}$ & $\begin{array}{l}1.50 \\
(1.44- \\
1.56)\end{array}$ \\
\hline Female & - & & & & & & \\
\hline 1 year & 161 & $\begin{array}{l}28.4 \\
(24.0- \\
32.8)\end{array}$ & $\begin{array}{l}23.5 \\
(22.2- \\
24.9)\end{array}$ & 684 & $\begin{array}{l}15.0 \\
(13.9- \\
16.2)\end{array}$ & $\begin{array}{l}16.6 \\
(15.5- \\
17.7)\end{array}$ & $\begin{array}{l}1.42 \\
(1.30- \\
1.55)\end{array}$ \\
\hline 3 year & 358 & $\begin{array}{l}23.9 \\
(21.4- \\
26.4)\end{array}$ & $\begin{array}{l}20.8 \\
(20.0- \\
21.6)\end{array}$ & 1,587 & $\begin{array}{l}12.9 \\
(12.3- \\
13.5)\end{array}$ & $\begin{array}{l}13.9 \\
(13.2- \\
14.5)\end{array}$ & $\begin{array}{l}1.49 \\
(1.43- \\
1.55)\end{array}$ \\
\hline 5 year & 520 & $\begin{array}{l}24.1 \\
(22.0- \\
26.1)\end{array}$ & $\begin{array}{l}21.7 \\
(21.1- \\
22.4)\end{array}$ & 2,366 & $\begin{array}{l}12.9 \\
(12.4- \\
13.4)\end{array}$ & $\begin{array}{l}13.6 \\
(13.1- \\
14.1)\end{array}$ & $\begin{array}{l}1.62 \\
(1.54- \\
1.70)\end{array}$ \\
\hline Overall & 711 & $\begin{array}{l}23.8 \\
(22.1-\end{array}$ & $\begin{array}{l}22.6 \\
(22.0-\end{array}$ & 3,603 & $\begin{array}{l}12.6 \\
(12.2-\end{array}$ & $\begin{array}{l}13.2 \\
(12.8-\end{array}$ & $\begin{array}{l}1.73 \\
(1.66-\end{array}$ \\
\hline
\end{tabular}


CAS, coronary artery spasm; ID, incidence density; Cl, confidence interval; SHR, subdistribution hazard ratio.

*Adjusted for inverse probability of treatment weighting by propensity score.

${ }^{a}$ The inverse probability of treatment weight was calculated separately in each sex.

bIncidence density: number of events per 1000 person-years.

\section{Figures}

\section{Data source 1}

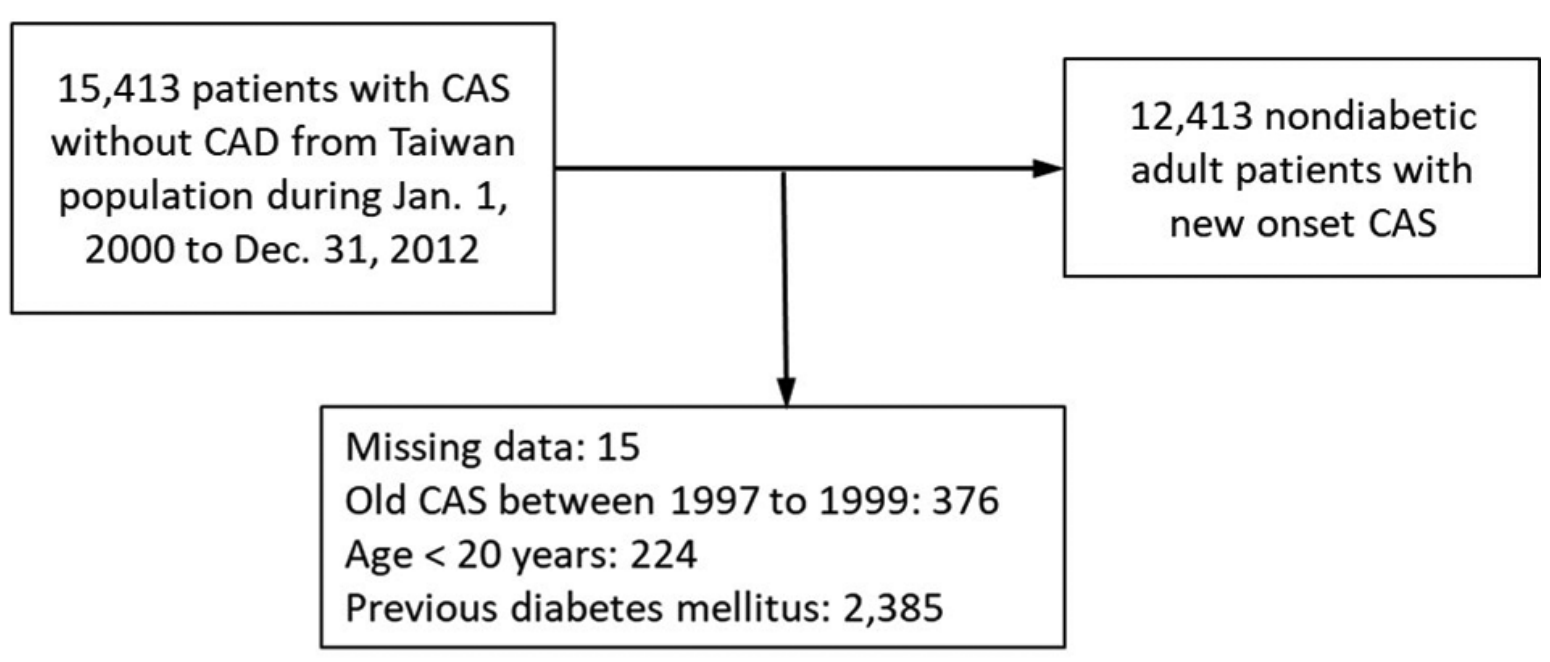

\section{Data source 2}

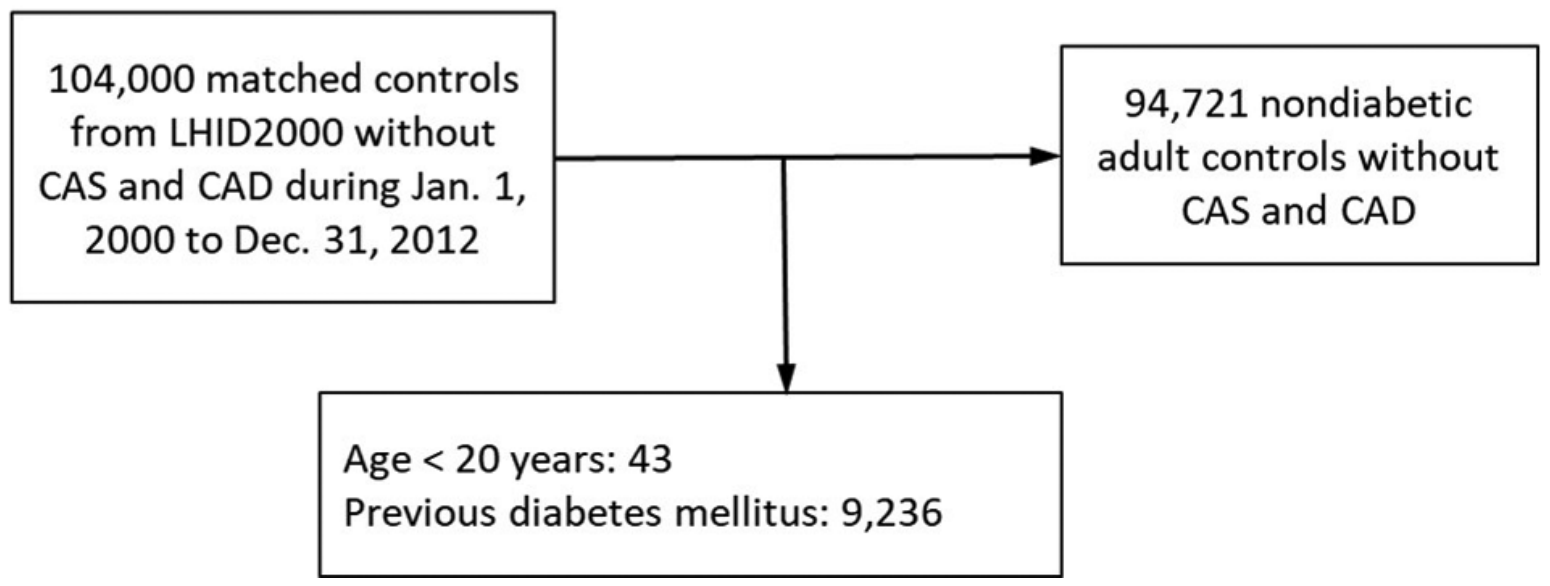

\section{Figure 1}

Study flow diagram. CAD, coronary artery disease; CAS, coronary artery spasm; LHID200, Longitudinal Health Insurance Database 2000 


\section{Data source 1}

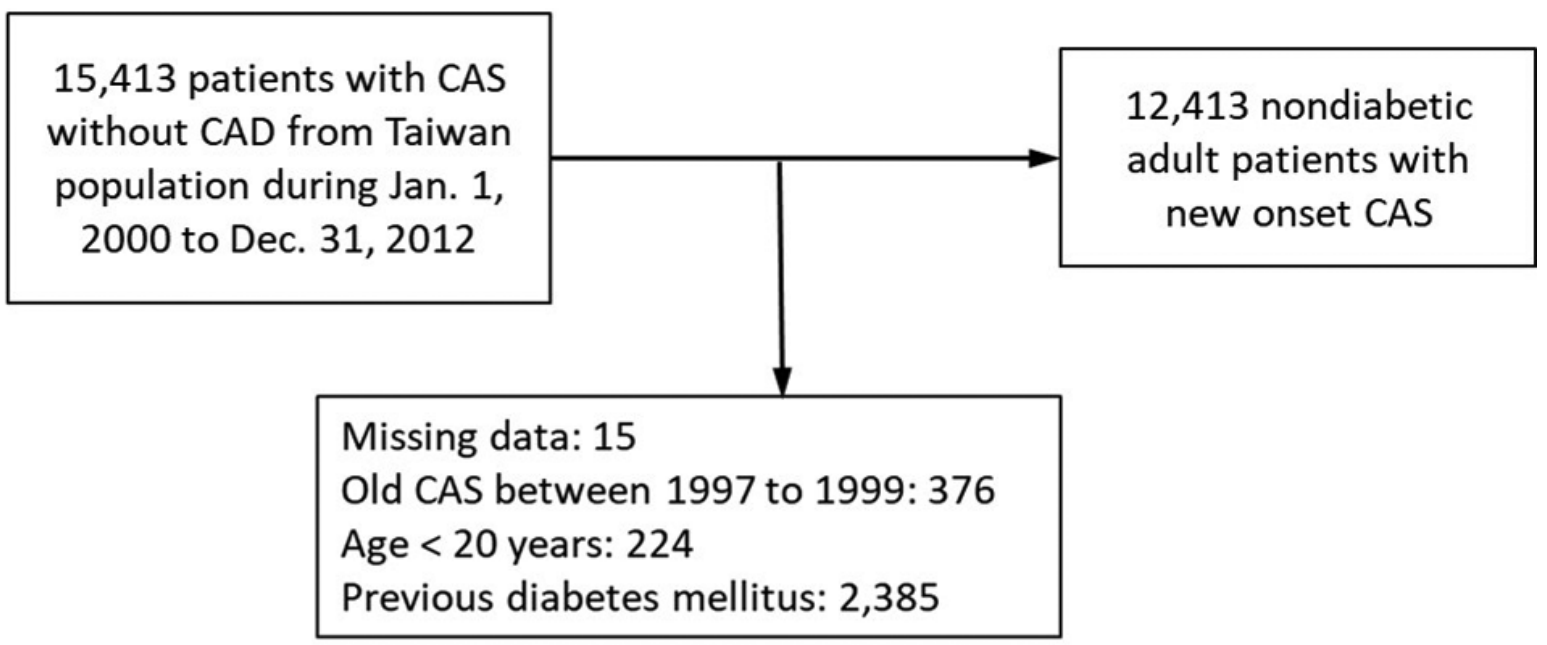

\section{Data source 2}

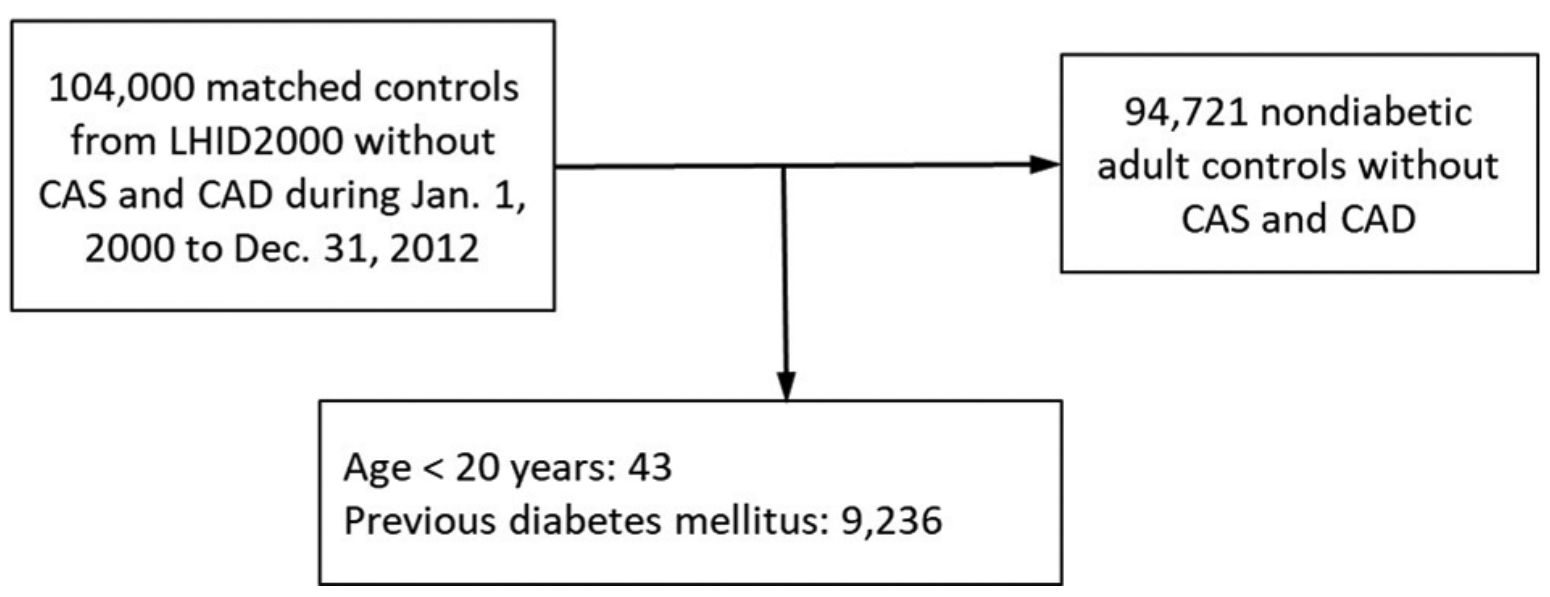

Figure 1

Study flow diagram. CAD, coronary artery disease; CAS, coronary artery spasm; LHID200, Longitudinal Health Insurance Database 2000 
A. Primary analysis

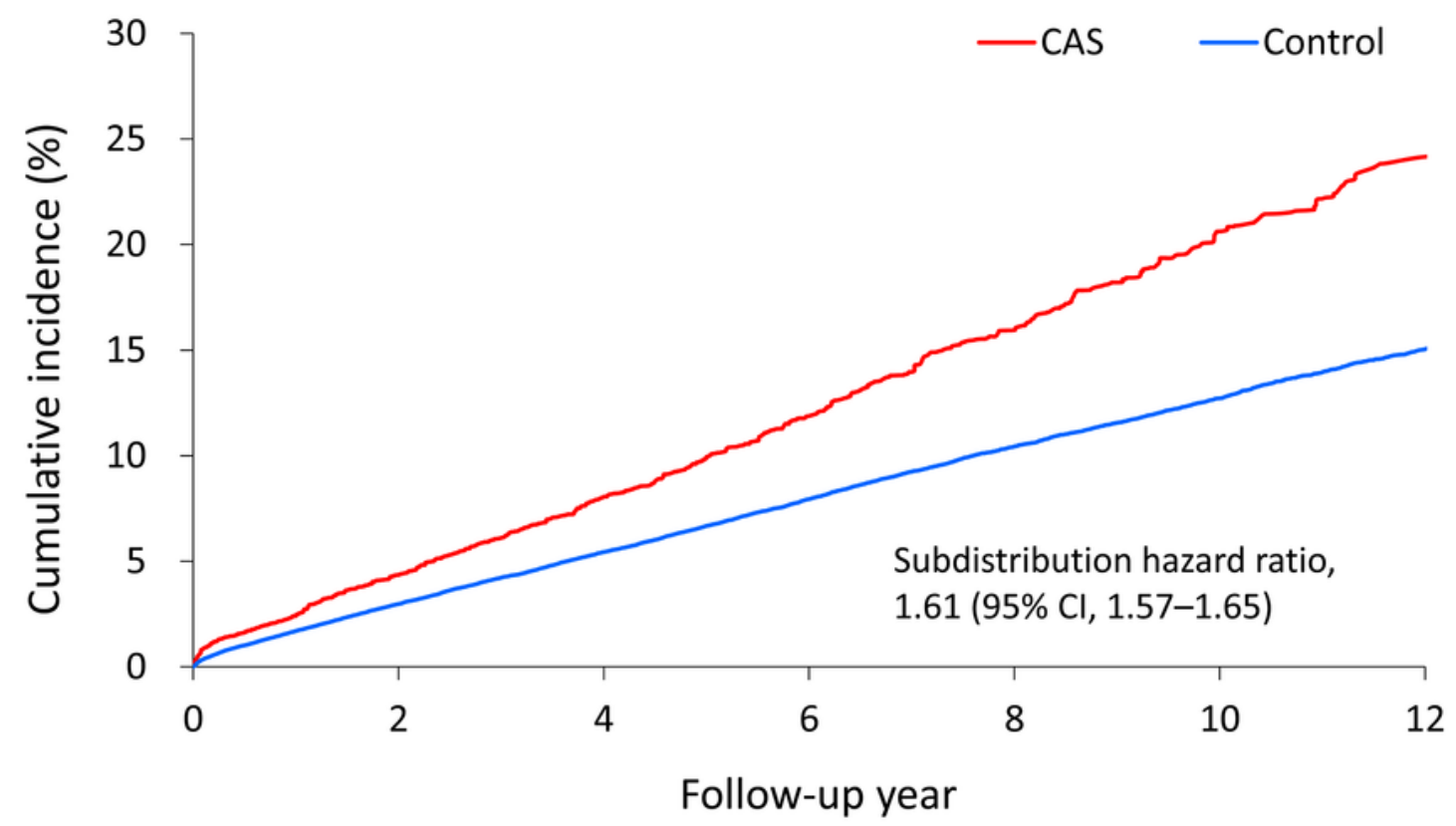

\begin{tabular}{|c|c|c|c|c|c|c|c|}
\hline \\
\hline CAS & 100 & 76.0 & 54.3 & 34.5 & 20.2 & 10.0 & $\begin{array}{l}(\%): \\
76.0\end{array}$ \\
\hline Control & 100 & 85.6 & 67.3 & 50.4 & 35.4 & 22.0 & 10.2 \\
\hline
\end{tabular}

B. Sensitivity analysis

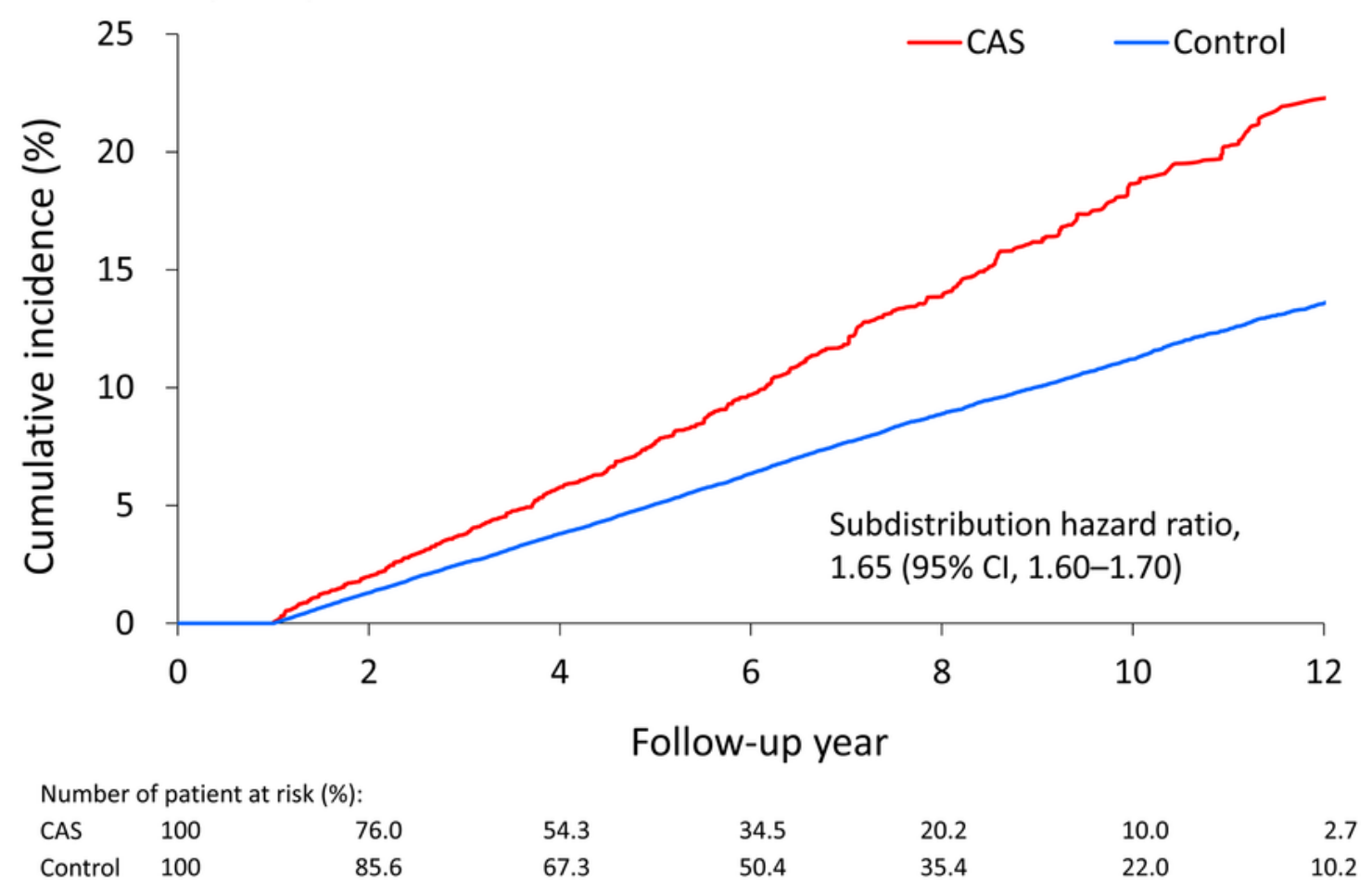

Figure 2

Cumulative incidence of diabetes associated with CAS. A. The cumulative incidence of diabetes in the nondiabetic patients with CAS and control subjects in the primary analysis by inverse probability of treatment weighting. $B$. The sensitivity analysis by censoring patients diagnosed as incident diabetes within 1 year after the index date. CAS, coronary artery spasm 
A. Primary analysis

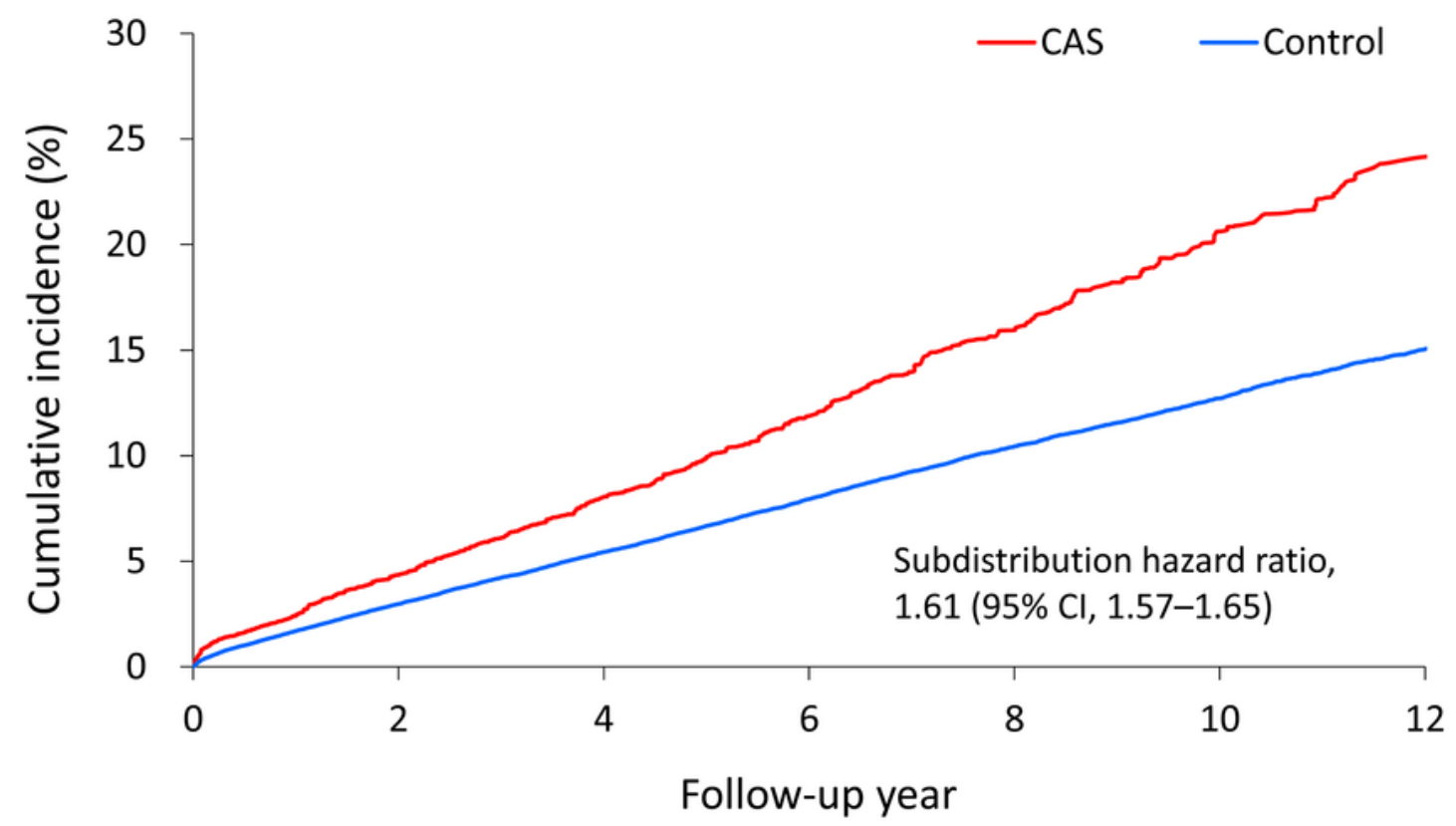

\begin{tabular}{|c|c|c|c|c|c|c|c|}
\hline \\
\hline CAS & 100 & 76.0 & 54.3 & 34.5 & 20.2 & 10.0 & $\begin{array}{l}(\%): \\
76.0\end{array}$ \\
\hline Control & 100 & 85.6 & 67.3 & 50.4 & 35.4 & 22.0 & 10.2 \\
\hline
\end{tabular}

B. Sensitivity analysis

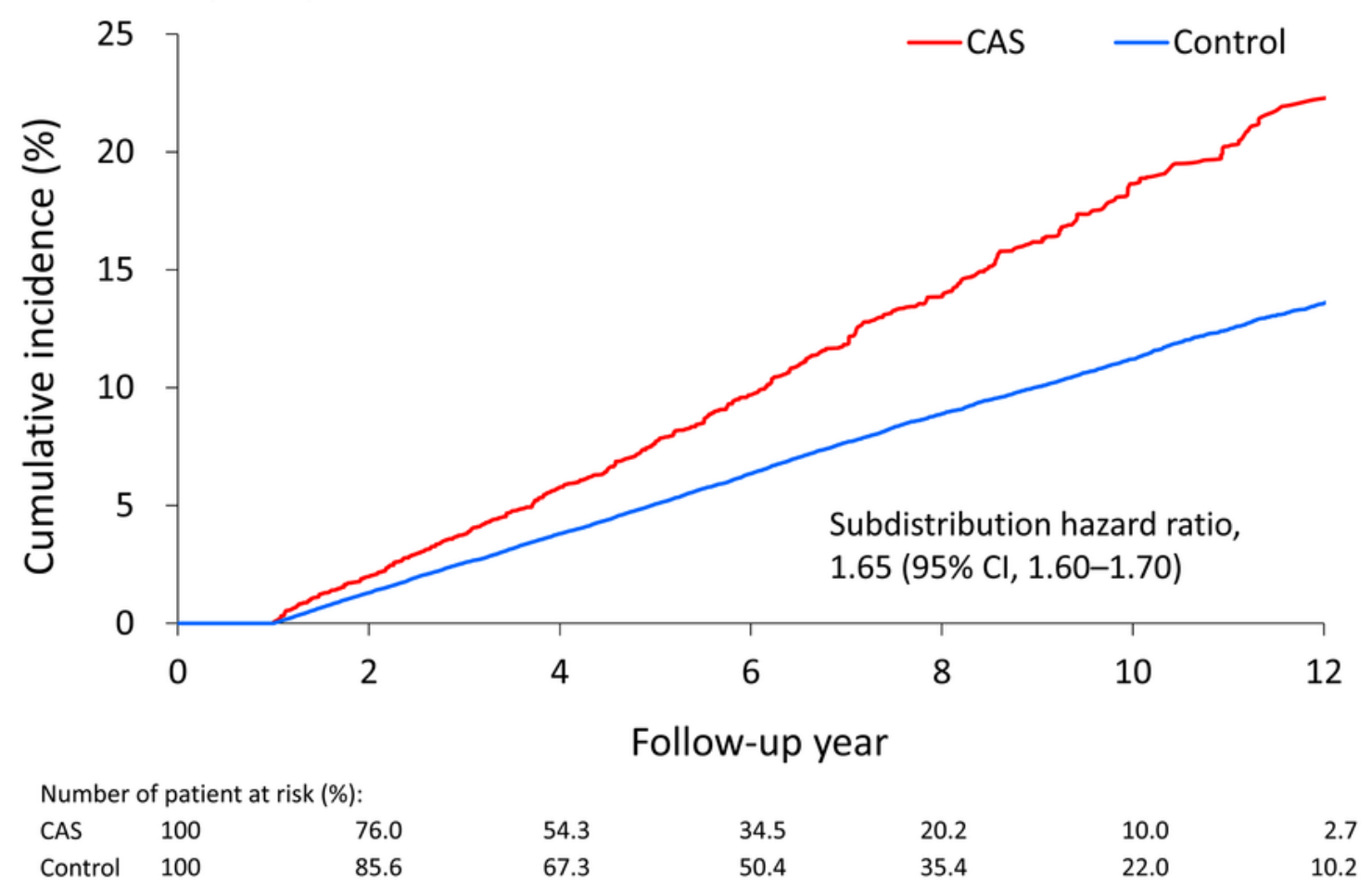

Figure 2

Cumulative incidence of diabetes associated with CAS. A. The cumulative incidence of diabetes in the nondiabetic patients with CAS and control subjects in the primary analysis by inverse probability of treatment weighting. $B$. The sensitivity analysis by censoring patients diagnosed as incident diabetes within 1 year after the index date. CAS, coronary artery spasm 


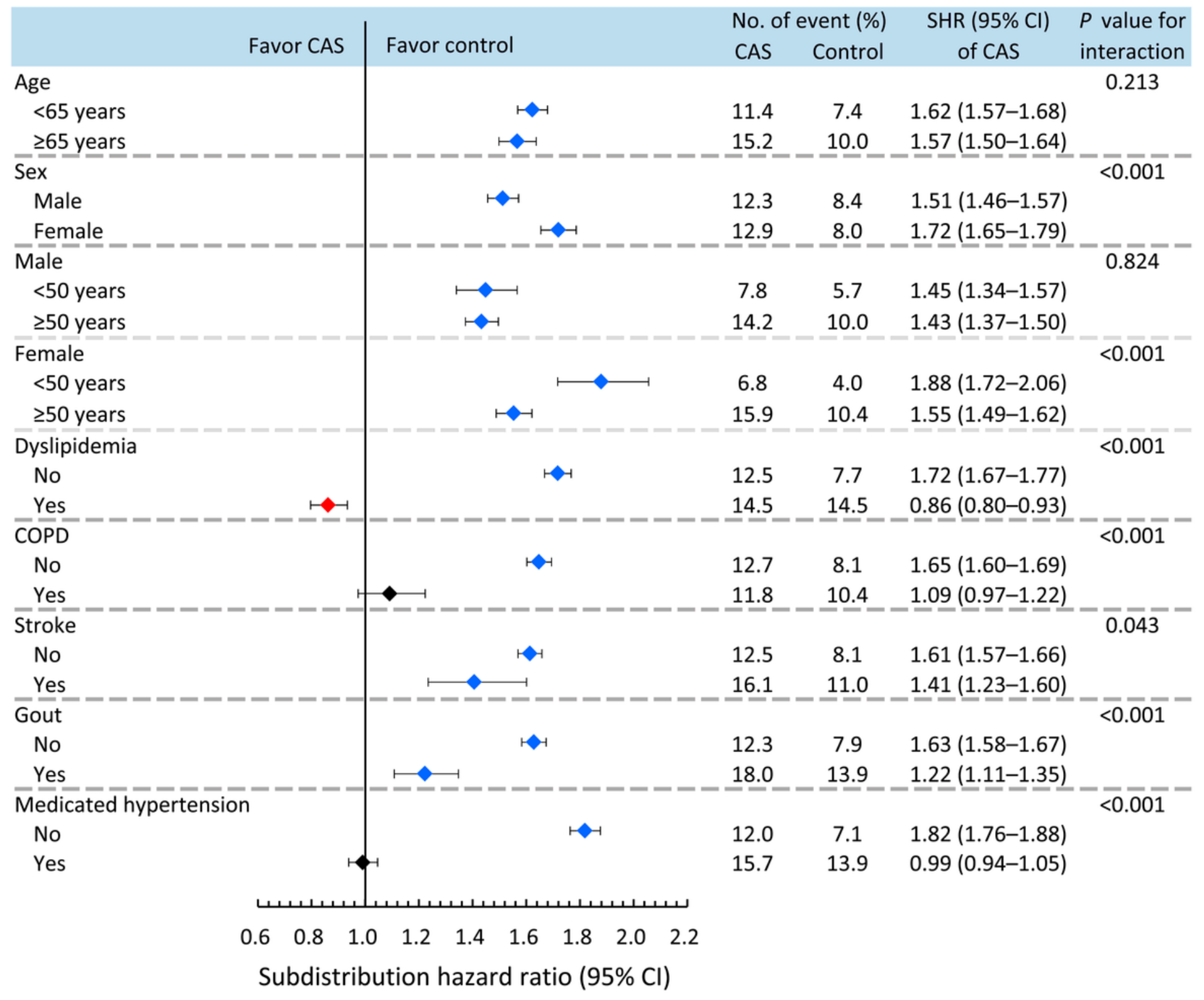

Figure 3

Pre-specified nondiabetic subgroup analysis for comparing risk of incident diabetes between CAS and control subjects. CAS, coronary artery spasm; COPD, chronic obstructive pulmonary disease 


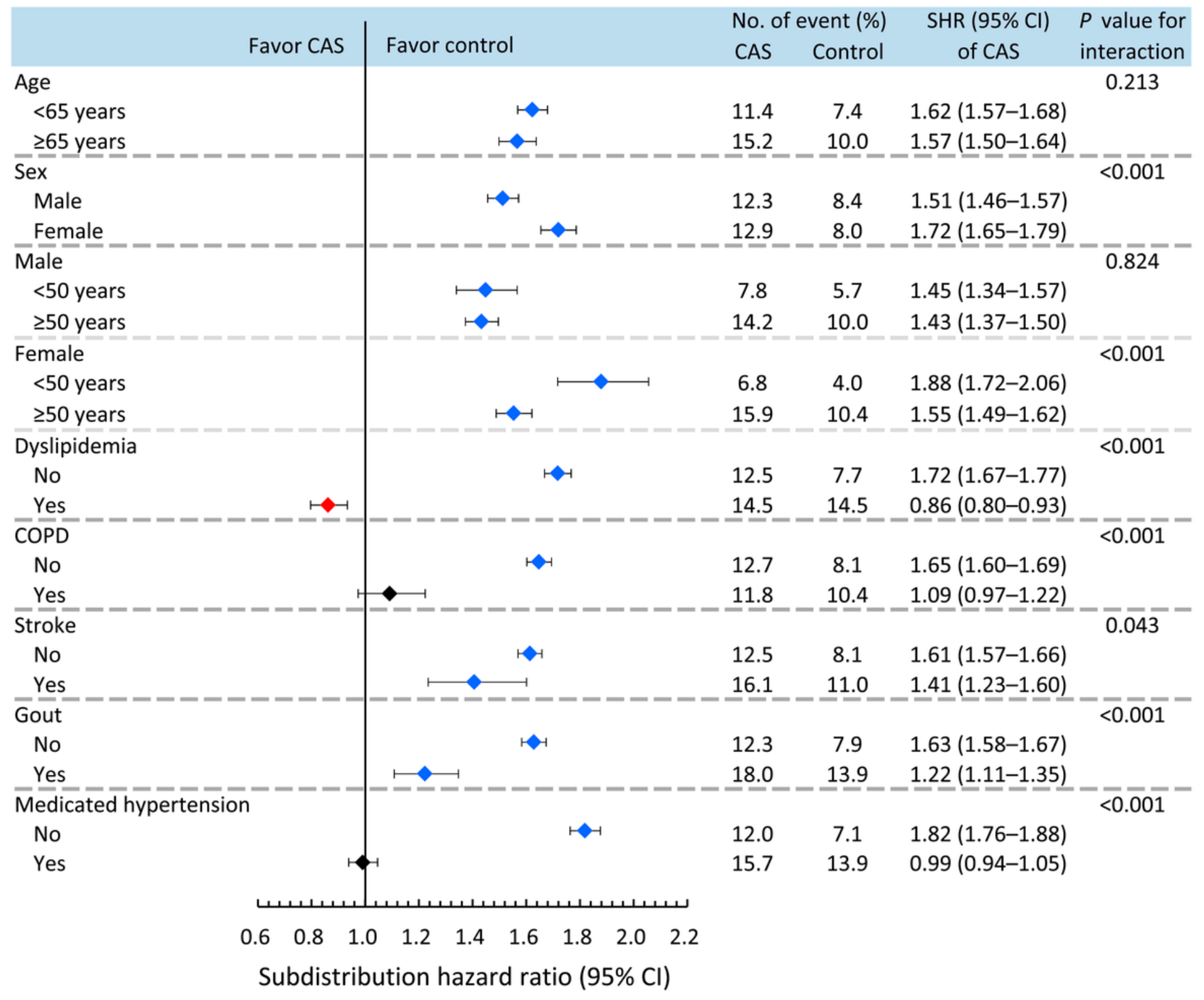

Figure 3

Pre-specified nondiabetic subgroup analysis for comparing risk of incident diabetes between CAS and control subjects. CAS, coronary artery spasm; COPD, chronic obstructive pulmonary disease 
A

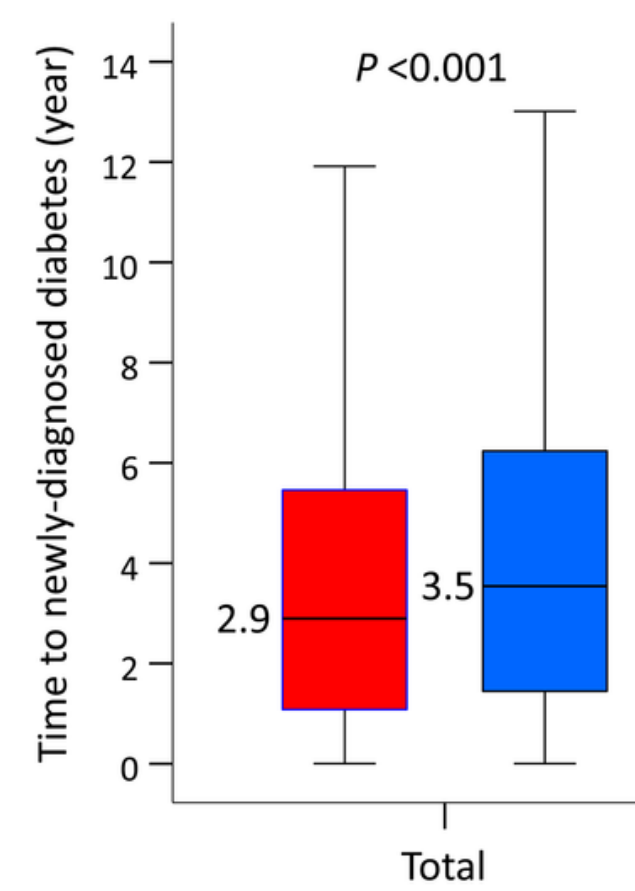

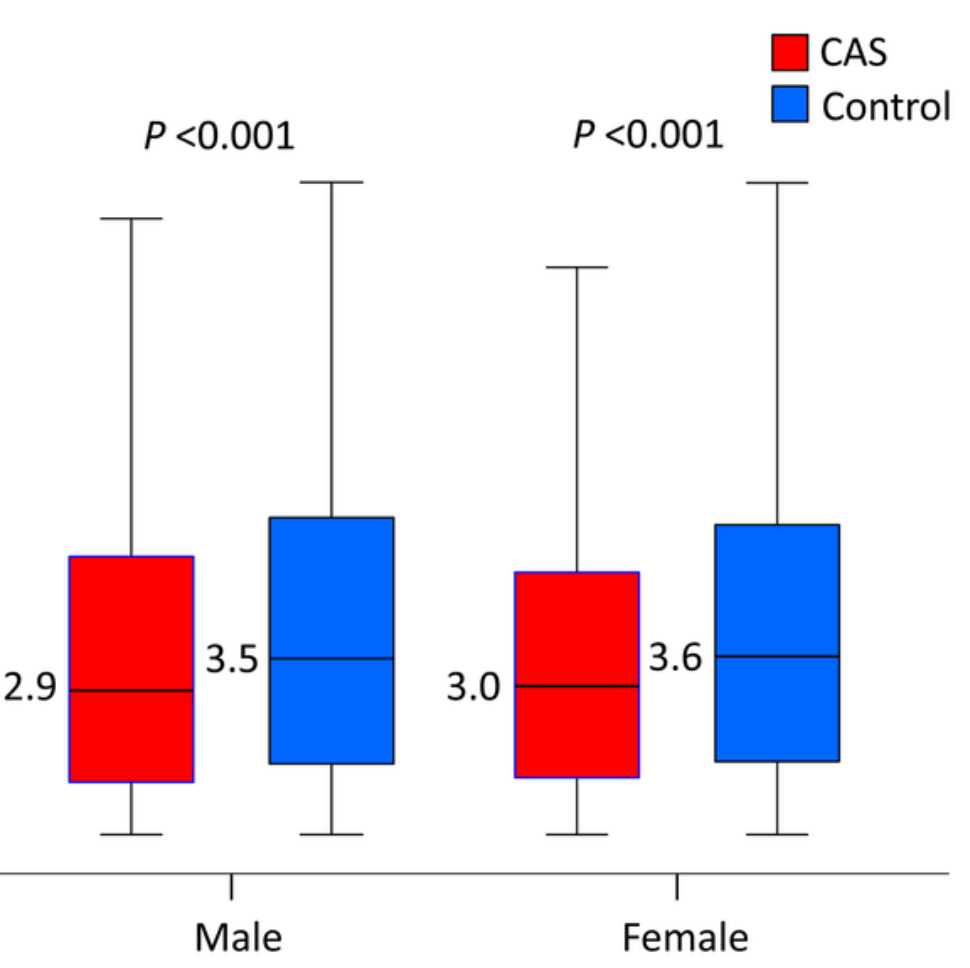

B

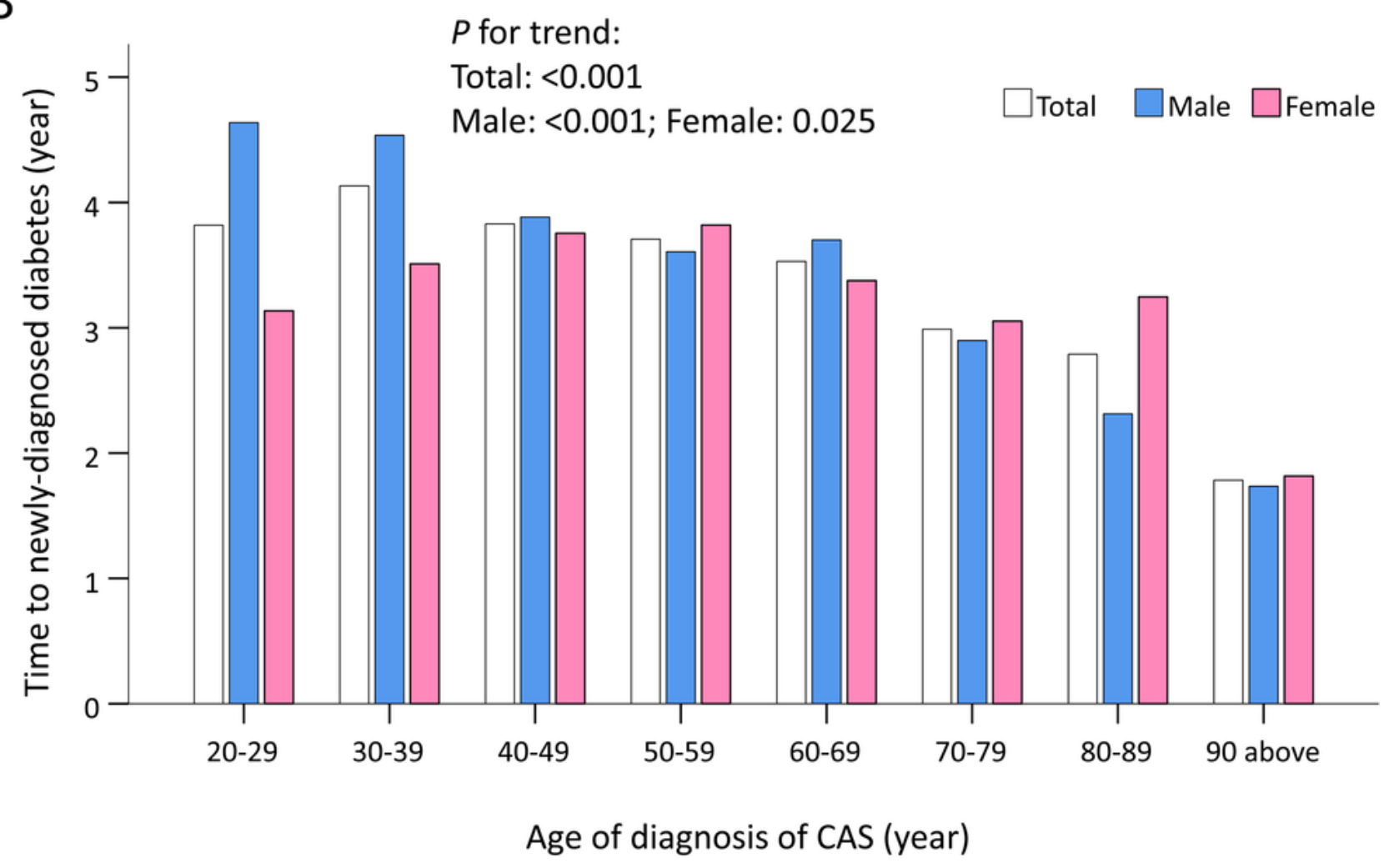

\section{Figure 4}

Time to incident diabetes in patients with CAS and the control subjects before IPTW. A. Time to incident diabetes in patients with CAS and the control subjects by sex. B. Time to incident diabetes in patients with CAS and the control subjects by sex and ages. CAS, coronary artery spasm; IPTW, inverse probability of treatment weighting 
A
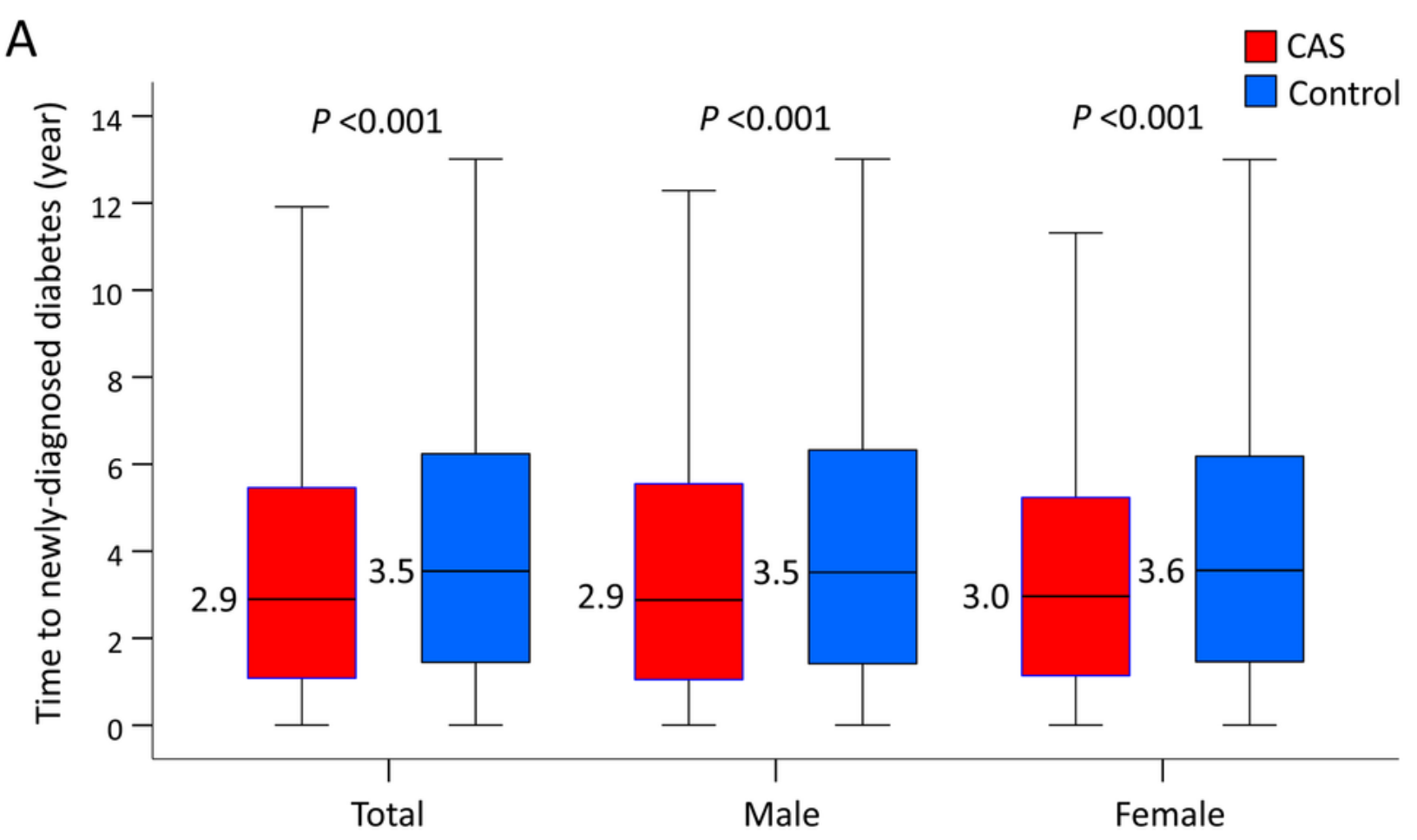

B

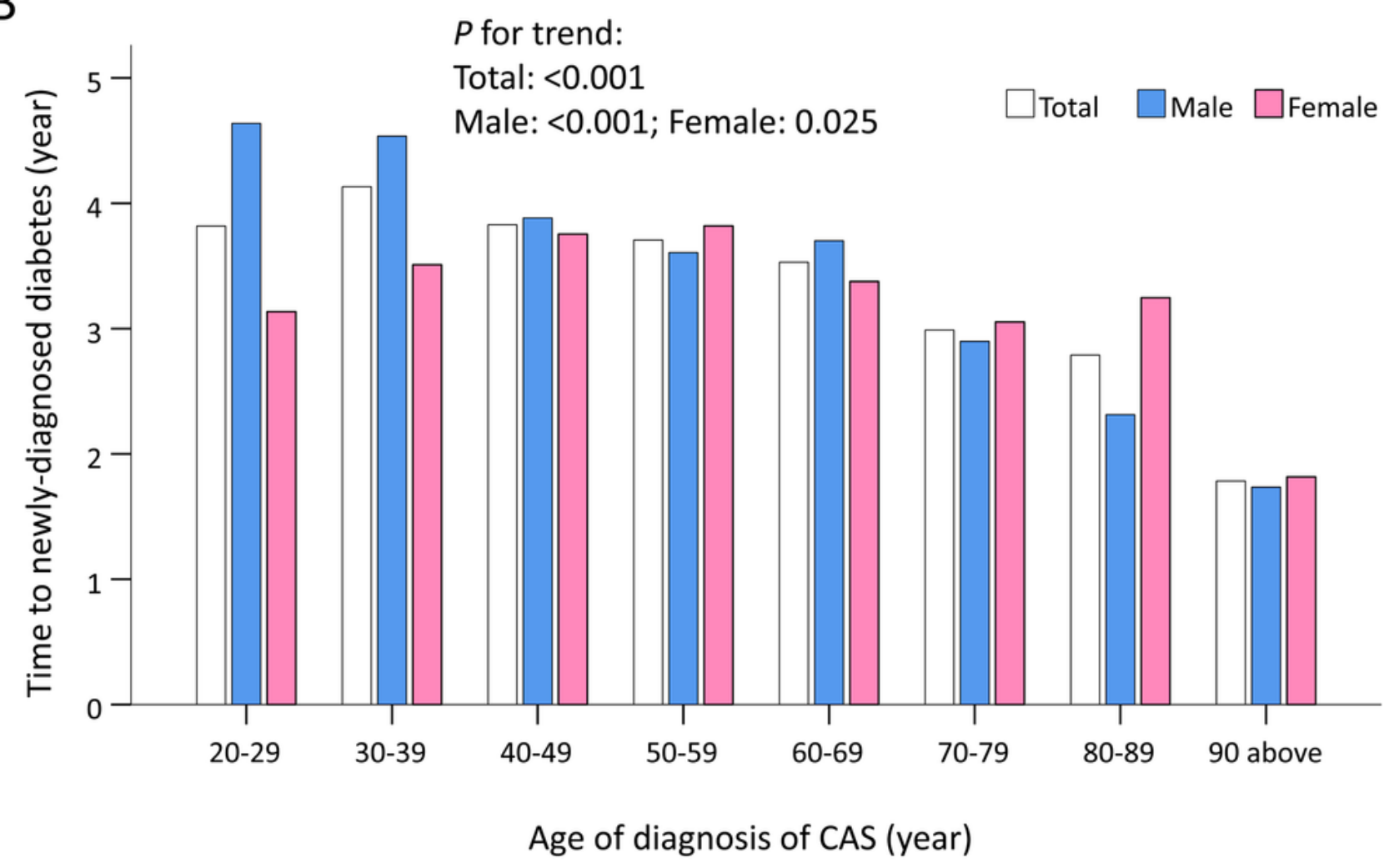

\section{Figure 4}

Time to incident diabetes in patients with CAS and the control subjects before IPTW. A. Time to incident diabetes in patients with CAS and the control subjects by sex. B. Time to incident diabetes in patients with CAS and the control subjects by sex and ages. CAS, coronary artery spasm; IPTW, inverse probability of treatment weighting 


\section{Supplementary Files}

This is a list of supplementary files associated with this preprint. Click to download.

- 20201117CASDMSupplementarydataR5.docx

- 20201117CASDMSupplementarydataR5.docx 